\title{
Natural selection and adaptive evolution of leptin
}

\author{
ZOU Guo ${ }^{1}$, ZHANG YaPing ${ }^{1,3} \& \mathrm{YU} \mathrm{Li}^{1,2^{*}}$ \\ ${ }^{1}$ Laboratory for Conservation and Utilization of Bio-resource, Yunnan University, Kunming 650091, China; \\ ${ }^{2}$ Key Laboratory for Animal Genetic Diversity and Evolution of High Education in Yunnan Province, Yunnan University, Kunming 650091, \\ China; \\ ${ }^{3}$ State Key Laboratory of Genetic Resources and Evolution, Kunming Institute of Zoology, Chinese Academy of Sciences, Kunming 650223, China
}

Received April 12, 2012; accepted June 20, 2012; published online January 21, 2013

\begin{abstract}
Leptin is an adiposity-secreted hormone that is pivotal in regulating feeding behavior, energy metabolism and body mass. The study of leptin has been of crucial importance for public health and pharmaceutical intervention given its role in obesity. Generally, leptin is highly conserved due to its functional importance. However, episodes of rapid sequence evolution and positive selection have been observed in some mammalian species, indicating that the leptin functions in these animals may have undergone adaptive modification to their environments. In this article, we review the adaptive evolution of leptin and its potential functional consequences. This review is expected to guide future research of molecular evolution and functional assays of this gene, and also to provide a theoretical foundation for the use of leptin in therapeutic applications.
\end{abstract}

natural selection, adaptive evolution, leptin, leptin receptor

Citation: Zou G, Zhang Y P, Yu L. Natural selection and adaptive evolution of leptin. Chin Sci Bull, 2013, 58: 2104-2112, doi: 10.1007/s11434-012-5635-8

The relationship between the adaptations of an organism to different ecological niches with genetic changes (e.g. the change of genes) has been one of the essential subjects in the study of life sciences. Accordingly, the mechanism underlying how organisms adapt to different living environments at molecular level has fascinated evolutionary biologists [1-9].

Metabolism is a series of biochemical reactions, allowing organisms to exchange materials and energy with the environment. These processes control growth, reproduction and behavior of organisms. Although the mechanisms of increased energy utilization are likely to be complex, one important component involves the activation of adipose tissue [10].

Leptin, encoded by the obese gene, is a hormone that mainly secreted by adipose tissue. It is important in regulating feeding behavior, energy metabolism and body mass [11-16]. The level of plasma leptin is generally regarded as a signal to direct the central nervous system (CNS) to regu-

*Corresponding author (email: yuli1220@yahoo.com.cn) late food intake and energy expenditure, which is an important pathway of metabolism to maintain constancy of the adipose mass $[12,14,17,18]$. The mutation of $o b$ gene results in a myriad of disturbance of metabolism $[12,19]$. Mice that are homozygous (ob/ob mouse) for mutations in this gene exhibit a profound obesity resulting from defects in energy expenditure, food intake and nutrient partitioning [12,20,21]. In humans, mutation of this gene results in a profound obesity and type II diabetes [12,20-23]. Therefore, due to its critical role in obesity, the study of leptin will shed insight into molecular mechanism of energy homeostasis, future pharmaceutical intervention and public health [9,10,24].

The leptin gene, spanning over $4.5-\mathrm{kb}$, consists of three exons and two introns [9,25]. The coding exons (exons 2 and 3) are $501 \mathrm{bp}$ in length in total. Leptin contains an amino-terminal signal peptide (21 residues) and a mature peptide (146 residues), with four $\alpha$-helices (helices A-D) and a distorted segment $\mathrm{E}$ in the CD loop [9,26-28] (Figure 1).

Generally, leptin appears to be highly conserved due to its functional importance [12,29-32]. However, episodes of rapid sequence evolution and positive selection have been 


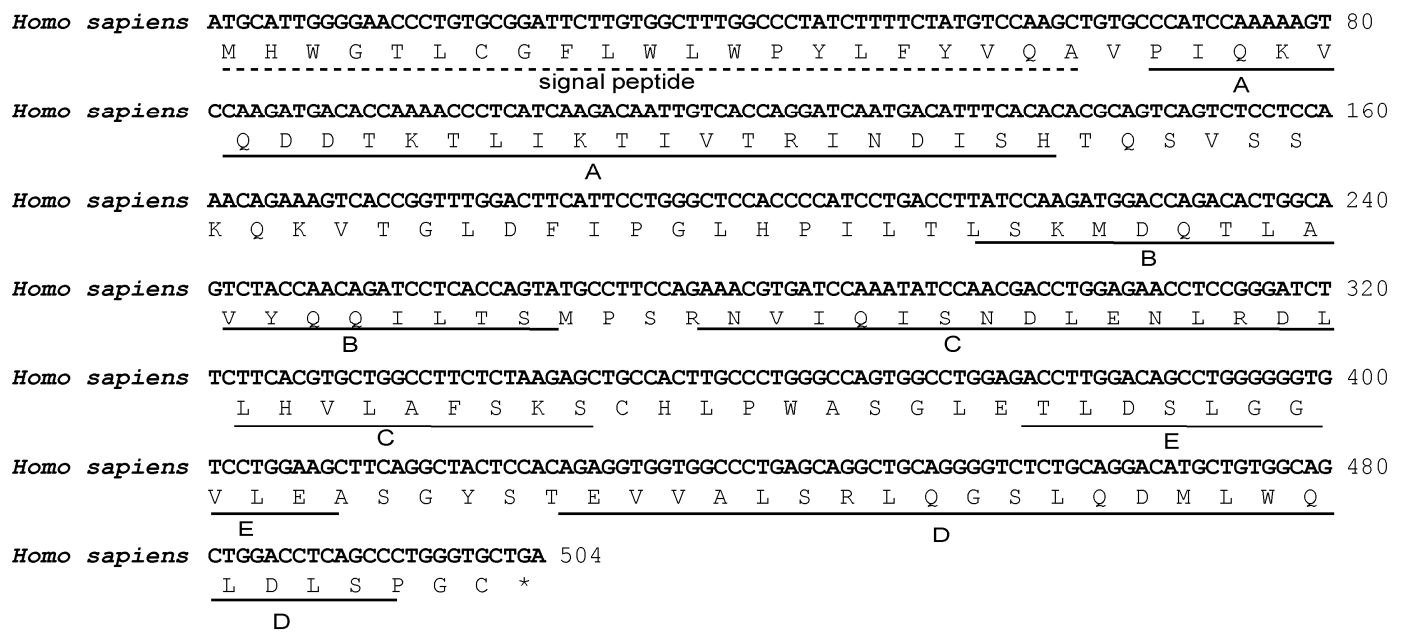

Figure 1 Human leptin sequence [33,40]. The signal peptide (1-21) is indicated by dotted line and the helices A-D are shown in solid lines. Helix E is a distorted segment in the CD loop.

documented in seals [9,33], whales [9], plateau pikas [34,35], primates [24,36-44] and bats [44]. The leptin gene duplication events were also observed in teleosts, which may be associated with tetraploidy [45]. These intriguing findings indicate that the leptin functions in these animals may have undergone adaptive modification to their environments.

In this article, we review the adaptive evolution of leptin and its potential functional consequences (Table 1). This review is expected to guide future research of molecular evolution and functional assays of this gene, and also to provide a theoretical foundation for the use of leptin in therapeutic applications.

\section{Leptin evolution and high-altitude adaptation}

Organisms that are living in highlands and those have been survived in the high altitude environment for millions of years have evolved various behavioral and physiological strategies to overcome the environmental challenges, which are characterized by very low temperature and hypoxia $[35,46,47]$. Such extreme environmental stress can drive certain proteins of these high-altitude species evolve rapidly and create a new series of metabolism reactions $[35,48]$. Attention of the earlier studies investigating the molecular evolutionary mechanism of adaptation to high altitude environment have been largely concentrated on mitochondrial DNA (mtDNA), which is the "energy factories" of animal cells and pivotal in oxygen consumption and energy metabolism [49]. Mt cytochrome $c$ oxidase, NADH dehydrogenase and cytochrome $b$ genes have been indicated in mammalian highland adaptation [4,49-56]. Recently, growing investigations have been performed from the perspective of nuclear genes, e.g. hemoglobin [57-60] and hypoxia inducible factor (HIF) pathway genes [61-67].

Leptin is well-known for its crucial roles in energy homeostasis. Given that changes of energy metabolism are remarkable for those species survive in cold regions at high altitudes, leptin thus becomes an important candidate gene for high-altitude adaptation studies. By utilizing pikas (order Lagomorpha: family Ochotonidae), which live in the Qinghai-Tibet Plateau (average altitude $>3000 \mathrm{~m}$ ), as an animal model, Yang et al. [35] examined their leptin gene variations. Intriguingly, they not only showed that the evolutionary rate of plateau pika leptin was accelerated, but

Table 1 Summary of the presence of positive selection of leptin on different lineages/species examined to date and potential physiological function

\begin{tabular}{|c|c|c|c|}
\hline Order & Lineage/Species & Potential function & References \\
\hline Lagomorpha & Pika & Cold adaption & {$[34,35]$} \\
\hline Carnivora & Seal & Pulmonary surfactant production & [9] \\
\hline Cetacea & Whale & Pulmonary surfactant production & [9] \\
\hline Chiroptera & Bat & Hibernating adaption & [44] \\
\hline \multirow[t]{4}{*}{ Primates } & Hominidea & Reproductive and/or dietary and/or other physiological functional adaption & {$[24,36-39,41,43,44]$} \\
\hline & Gorilla & Reproductive and/or dietary and/or other physiological functional adaption & [24] \\
\hline & Macaque & Reproductive and/or dietary and/or other physiological functional adaption & {$[24,36-38,43]$} \\
\hline & Mouse Lemur & Reproductive and/or dietary and/or other physiological functional adaption & [44] \\
\hline
\end{tabular}


also found the sign of positive selection acting on it. In total, 20 adaptive sites were identified, 9 of which located within the functionally significant segment (85-119 residues) of leptin $[35,68,69]$. This segment is believed to be a domain that associated with weight regulation in previous studies $[68,69]$. In addition, the ATP synthase $\alpha$ and $\beta$ subunit signature site was observed only in plateau pika lineages [35]. They assume that the environment factor that drives the adaptive evolution of plateau pika leptin is most likely to be the extremely low temperature. Subsequently, Yang et al. [34] compared the expression levels of leptin in brown adipose tissue and the hypothalamus between plateau pika and human to test the above hypothesis. They observed that pika leptin appears superior than human leptin in inducing adaptive thermogenesis, which provides evidence that the leptin gene may indeed pivotal in pikas' cold adaptations associated with highland environment [34,35].

Except for humans, the Chinese snub-nosed monkeys inhabit with the highest altitudinal distribution [70-73]. In order to examine whether nature selection and adaptive evolution of leptin gene act on other high-altitude species, Wang et al. [74] analyzed leptin genes of the Chinese snub-nosed monkeys (genus Rhinopithecus). The Chinese snub-nosed monkeys live in mountainous regions at high altitudes $(>2000 \mathrm{~m})$. Similar to plateau pikas, the energy metabolism strategy of them has changed under cold conditions [4]. By sequencing leptin genes from two Chinese snub-nosed monkeys ( $R$. bieti and $R$. roxellana), together with their lowland close relative $R$. avunculus and other Colobines, they found only 3 synonymous substitutions $(K \mathrm{~s})$ and no nonsynonymous substitutions $(\mathrm{Ka})$, indicating that the evolutionary pattern of leptin gene between Chinese snub-nosed monkeys and their lowland counterparts has no difference [74]. Inconsistent with Yang et al.'s [34,35] results, in which Ka was higher than Ks for pika leptin and leptin was considered as an important genetic factor to enhance fitness of the pikas' survival at high-altitude, Wang et al.'s [74] investigation indicates that leptin might not contribute much to the adaptation of high-altitude of Chinese snub-nosed monkeys $[34,35,74]$. In this regard, the adaptive genetic basis of leptin, which was detected in plateau pika, does not exist in all the high-altitude organisms, at least in Chinese snub-nosed monkeys. Other candidate genes involved in energy expenditure are more likely to contribute to the adaption to cold and hypoxia in the high-altitude environment of Chinese snub-nosed monkeys, such as hemoglobin $[74,75]$, myoglobin [74,76], transforming growth factor- $\beta$ (TGF- $\beta$ ) [74,77], and hypoxia-in-ducible factor1(HIF1) $[74,78]$ as well as the mt DNA $[51,79,80]$.

\section{Leptin evolution and aquatic environment adaptation}

Compared with the terrestrial mammals, marine mammals are a special and unique mammalian group, which have developed a series of physiological and behavioral characteristics for their adaptation to the aquatic environments [7,81]. However, investigations underlying the relationship between the genetic changes of marine mammals and their adaptation to underwater life are still limited [7,81,82]. Marine mammals have been well-known for evolving a modified and adapted fat deposit regulation and energy metabolism for their survival associated with the blubber layer [83-85]. Blubber layer is the fundamental tissue that stores energy, which is important to protect marine mammals from cold water environment [83]. Therefore, as naturally obese mammals, the marine mammals provide a good study model for the exploration of association between the leptin and the body fat regulation adaptation. Indeed, in previous physiological assays, leptin has been intensely investigated in marine mammals $[86,87]$. However, no evidence suggests positive correlation between the body fat mass and levels of plasma leptin in the seal and sea lion species examined so far, indicating that leptin may not mainly function in body fat regulation and energy reserves of marine mammals, but associate with other physiological process $[9,33]$.

Hommand et al. [33] explored leptin expression pattern and the possible role of it in gray seal (Halichoerus grypus) and harbor seal (Phoca vitulina) [33]. Interestingly, they identified substantive amino acid substitutions unique in seal leptin. Furthermore, these amino acid substitutions are found to locate in the most conserved domains of helices A-D of leptin, implying that they are most likely to change the structure of leptin and have an influence on the function of this protein [26,33]. Another important finding from Hommand et al.'s [33] research is the observation of an uncommon expression of leptin in the lung tissue of seal [33]. They therefore proposed an interesting hypothesis that leptin in marine mammals plays an important role in a physiological function other than fat deposit regulation and energy metabolism, such as respiratory physiology. This hypothesis was indirectly argued for by the latter investigation of $\mathrm{Yu}$ et al. [9], in which leptin of more marine mammals, especially whales, was examined.

In Yu et al.'s [9] study, they found significant evidence of positive selection and identified several adaptive sites in toothed whales (suborder Odontoceti of Cetacea) and seals (family Phocidae of Pinnipidia), whereas no positive selection and adaptive sites were detected in baleen whales (suborder Mysticeti of Cetacea) and sea lions (family Otariidae of Pinnipedia). According to this result, Yu et al. [9] proposed that the driving forces for positive selection on toothed whales and seals leptins identified are not related to the adaptation to improve the fat deposit regulation and energy metabolism in these marine mammals because if such selection is driven solely by the difference in functions of fat deposits and the regulation of energy balance between terrestrial and marine mammals, then positive selection should occur in all the marine mammals examined. 
They therefore infer that leptin is probably involved in other functions for toothed whales and seals. Previous diving behavioral studies of marine mammals showed that toothed whales and seals generally live in an underwater and deep-sea environment, whereas baleen whales and sea lions survive near the surface of the water and does not dive to great depths. Based on the diving behavior difference, $\mathrm{Yu}$ et al. [9] supposed that their results might reflect the increased demand for either hypoxia, pulmonary or circulatory adaptations of the deep-diving toothed whales and seals. Therefore, the extended analyses from Yu et al. [9] provide evidence supporting the hypothesis proposed by Hammond et al.'s [33] report that leptin is most likely to associate with the respiratory physiology of seals, e.g., in the respect of pulmonary surfactant production.

\section{Leptin evolution and hibernation adaptation}

Hibernation is an important strategy for organisms to tolerate food shortage and low temperature conditions [44,88-90]. During the periods of hibernation, adipose tissue plays as the fundamental source of energy helping animals to sustain life [16]. A wealthy of previous physiological studies has shown that the level of serum leptin regulated the metabolism and food intake in hibernating species, including bats, squirrels, rats, and shrews [29,91-99].

In order to determine the potential structural and biochemical differences of leptin between hibernating and non-hibernating bats, He et al. [100] sequenced the leptin gene of Rhinolophus ferrumequinum (hibernating bat) and Rousettus leschenaultii (non-hibernating bat), and moreover, expressed the leptin proteins from these two bats species in Escherichia coli. Their results demonstrated that there were more amino acid substitutions in hibernating bats leptin than in non-hibernation bats [100]. In addition, the structural modeling analysis showed that the receptor binding site III of leptin, which is critical for signal transduction, from hibernating bats, has a helical structure, whereas the same region from non-hibernating bats and human leptin was predicted to be a random loop [26,100]. The expression assay suggested that hibernating bats leptin reveals a superior inhibitory capacity for growth of 3T3-L1 cells (adipose-like cells) than that of non-hibernating bats [100]. In summary, based on the observation of the differences in amino acid sequence, protein structure, and activity between the leptins of the non-hibernating and hibernating bats, He et al. [100] proposed a hypothesis that the hibernating bats leptin may have evolved from the non-hibernating bats leptin and assumed that leptin is likely to play an important role in adipose tissue metabolism of hibernating bats in terms of satisfying the need of special energy supply during the period of torpor [100].

Subsequently, by examining leptin of more hibernating and non-hibernating bat species, Yuan et al. [44] interest- ingly revealed signature of positive selection in hibernating lineages and evidence of relaxed selection in non-hibernating lineages. In addition, their sliding window analysis revealed that in hibernating bats, most domains of leptin exon 3 , especially in the $\mathrm{AB}$ loop and helix $\mathrm{D}$, demonstrate higher kalks ratios than that of non-hibernating bats [44]. In particular, 6 of 29 residue substitutions specific to hibernating bats were found in functionally significant segment (85-119) of leptin exon 3, and two of them are binding sites [44,68, 69], indicating that positive selection may affect the interaction of leptin with receptor. Notably, their biochemical analysis shows that hibernating bats leptin is more efficient in lipid degradation than non-hibernating bats leptin, which probably is the biological consequence of natural selection of hibernating bats leptin [44].

\section{Leptin evolution and other physiological functions}

Accumulating evidence has suggested that besides adipose tissues, leptin was also expressed in placenta, stomach, bone marrow, lung, and mammary epithelium [17,33,101-106] and was involved in placental and fetal growth regulation, brain development, gastric function, hematopoiesis, inflammation, and pulmonary surfactant production $[9,33$, 101,104-107]. Accordingly, besides fat regulation and energy metabolism, it is believed that leptin may also play important roles in other physiological functions.

In view of this, it is notable that there are considerable evolutionary studies suggesting action of positive selection on the leptin of primates [24,36-44] and speculating leptin function in primates has undergone modification with new tissue specificity or some more crucial physiologic functions, although the precise ecology and selective forces acting to produce these changes are not clear. Siltberg and Liberles [43] proposed a hypothesis that the natural selection of leptin gene in primate maybe responding to dietary and/or reproductive variation during the evolution of primates, which will be tested in future studies.

Thus, some researchers proposed that the utility of the widely-used rodent model for studying human obesity may be limited in pharmaceutical application, as evidenced by the difference of evolutionary pattern of primates and other mammalian leptin genes [24,36-38]. Intriguingly, these previous studies disagreed on the specific primate lineage on which the adaptive evolution occurred. Based on different methods used for assigning ancestral sequences and calculating the $\mathrm{Ka} / \mathrm{Ks}$ ratio [41], the exact numbers of positive selection throughout the primate lineages are not clear and from two to four lineages have been proposed (Figure 2). Benner, Trabesinger, and Schreiber [24], and Siltberg and Liberles [43] identified positive selection acting on 4 lineages, the lineages leading to hominoids, orangutans, gorillas and possibly, macaque (symbol $\star$ in Figure 2). 


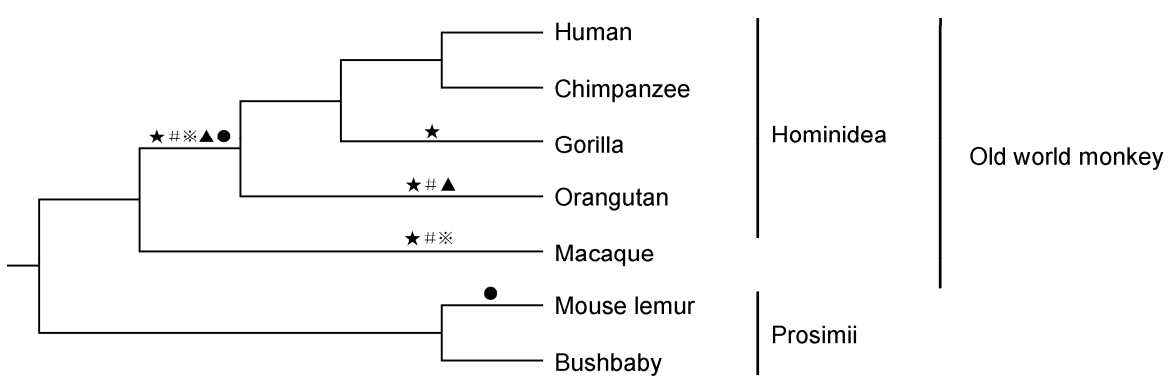

Figure 2 The primate lineages that were detected under positive selection in previous studies. $\star$ indicates those from Benner et al. [24] and Siltberg and Liberless [43]; \# indicates those from Benner et al. [37] and Benner and Gaucher [38]; ※ indicates those from Liberles et al. [41] and Berglund et al. [39]; $\boldsymbol{\Delta}$ indicates those from Benner et al. [36]; $\bullet$ indicates those from Yuan et al. [44].

Benner et al. [37] and Benner and Gaucher [38] detected positive selection on three lineages, the lineages leading to hominoids, orangutans, and macaque (symbol \# in Figure 2), whereas in Liberles [41] and Berglund et al. [39], two lineages leading to hominoids and possibly, macaque, showed evidence of positive selection (symbol $※$ in Figure 2). Benner et al. [36] suggested that two lineages leading to hominoids and orangutans, but not to hominoids and macaque, have undergone positive selection (symbol $\boldsymbol{\Delta}$ in Figure 2). Yuan et al. [44], however, provided evidence indicating that the lineages leading to hominoids and mouse lemur (Microcebus murinus, Prosimii) have undergone adaptive evolution (symbol • in Figure 2). Hence, identification of the precise patterns of leptin gene evolution in primates has been elusive.

It should be noted that in all the previous evolutionary studies of primate leptin, the sequences used were very limited, making current understanding of primate leptin gene evolution largely based on the analyses of very limited taxonomic sampling. Sampling additional primate taxa will be useful for assisting in discriminating among these alternative hypotheses, which is critical for learning the true evolutionary pattern of primate leptin and its subsequent biological outcomes.

\section{$5 \quad$ Leptin and leptin receptor co-evolution}

Leptin is thought to exert its profound physiological effects via direct binding to the leptin receptor (LPR) in the hypothalamus $[13,17,21]$. The leptin receptor is a large single-transmembrane-domain receptor of the class I cytokine receptor family and is coded by the diabetes $(d b)$ gene [10,108-111]. Homozygous mutant $d b / d b$ mice produce a syndrome that is phenotypically identical to the $o b / o b$ mouse $[108,109,112,113]$. In humans, the $L P R$ gene consists of 20 exons, spanning over $70 \mathrm{~kb}$ in chromosome 1q31 and encoding a huge protein of 1165 amino acids $[10,111,114]$, which consist of a 22 -amino-acids signal peptide and a huge mature peptide of 1143 amino acids, which contains three regions - the extracellular region (816 residues), the transmenmbrane region (23 residues) and the intracellular region (304 residues) (Figure 3) [10,111,115]. The extracellular region contains two cytokine receptor homology domains, i.e. cytokine receptor homology domain 1 (CRH1) and cytokine receptor homology domain 2 (CRH2) $[9,110,115,116]$. Based on previously studies, the CRH2 domain is essential for the interaction of leptin and its receptor $[9,115,117,118]$, and it bind to the site II in leptin $[9,110,115-118]$.

In contrast to other cytokines and their receptors, e.g., growth hormone $(\mathrm{GH})$ and the growth hormone receptor (GHR) $[119,120]$, and prolactin (PRL) and the prolactin receptor (PRLR) [121], the evolutionary pattern of leptin/receptor signaling system is still largely unknown. Some cytokines and their receptors have been shown to evolve in a coordinated manner [121], which is consistent with the ligand-receptor co-evolution hypothesis. It is interesting to know whether the $L P R$ shows a similar pattern of episodic evolution to that of leptin gene. So far, the only two evolutionary analyses of the $L P R$ are performed by Benner et al. [24] and Yu et al. [9], respectively. In Benner et al.'s [24] analyses of the extracellular region of primates $L P R$, although they predicted that the leptin receptor may have responded to selection in the primates, similar to that of leptin, however, they could not provide evidence of positive selection for $L P R$ and co-evolution of leptin and its receptor, because fewer mammalian $L P R$ genes were available for analysis than the corresponding leptin genes. In particular, only one $L P R$ sequence from human is included in the primate lineage of their study. In Yu et al.'s [9] study, they analyzed the representatives of marine mammals - Cetacea and Pinnipedia. Their study found no evidence of positive selection for $L P R$ across Cetacea and Pinnipedia lineages, which is a case contrasting to leptin of the two lineages, for which adaptive evolution has been indicated. Hence, the co-evolution of ligand-receptor pair is not observed at leptin and its receptor genes of the two marine mammalian lineages. The authors suggested that the different evolutionary patterns of leptin and LPR observed here may reflect multifunctionality of leptin and leptin receptor, and support the conclusion that the biological role of leptin varied from species to species [38]. In furture investigations, including more $L P R$ sequences from other mammalian species would 


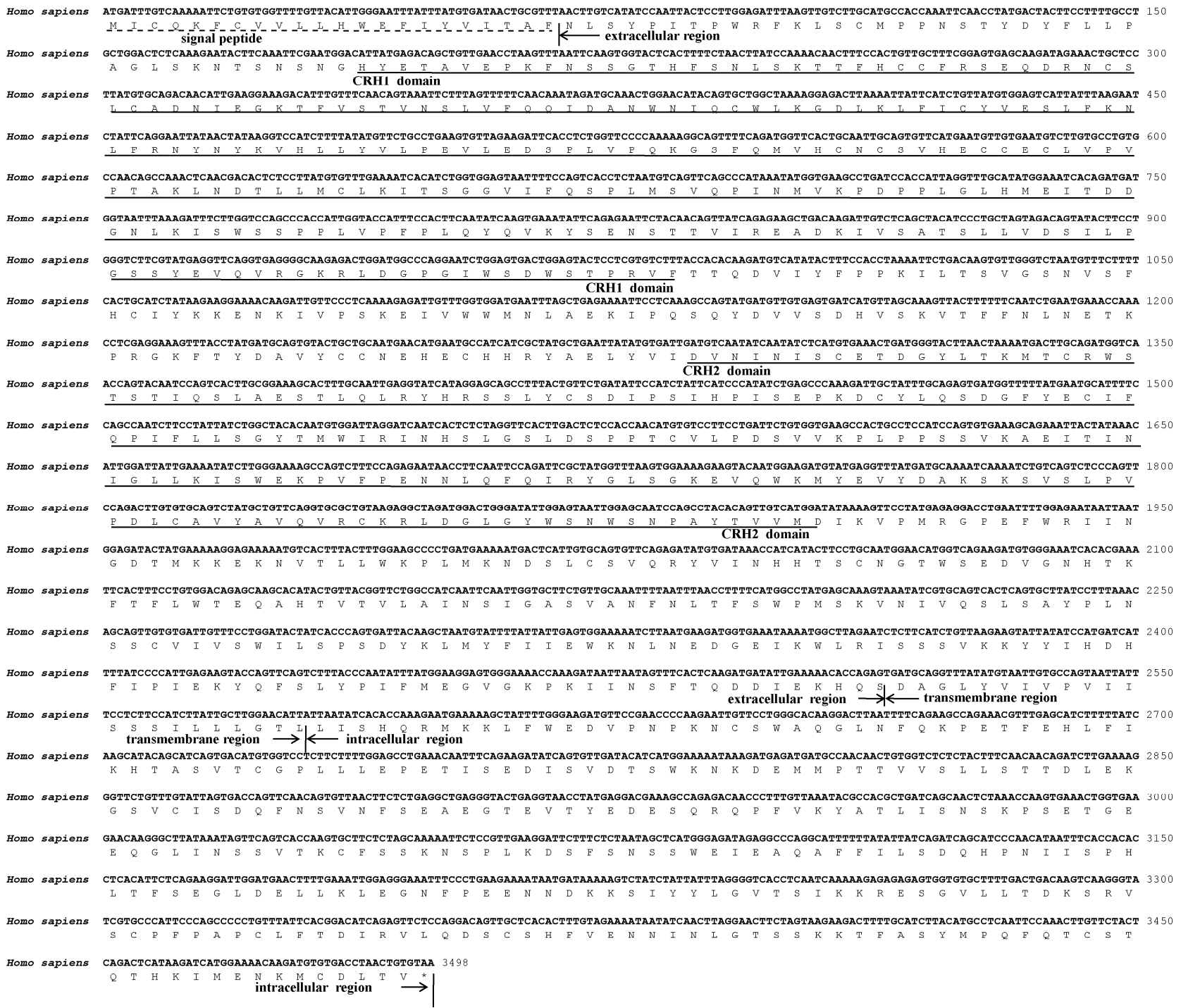

Figure 3 Human $L P R$ sequence [10,110,111,115,116]. The signal peptide (1-22) is indicated by dotted line and the extracelluar region (23-838), the transmenmbrane region (839-861) and the intracellular region (862-1165) are shown between arrows. The CRH1 domain and CRH2 domain are indicated in solid lines.

give a clearer and more complete picture of the co-evolution of leptin and LPR.

\section{Conclusion and perspectives}

As an essential hormone for regulation of appetite and body mass in mammals, the physiological significance and medical importance of leptin and its receptor gene assures that this hormone-receptor complex will remain a focus of future studies. Previous studies have made significant progress in the evolutionary history of leptin, revealing the evidence for episodic evolution of this gene in seals, whales, pikas, primates, and bats etc. (summarized in Table 1). More information on the structure, function, and evolution of leptin/receptor genes in mammals is required for resolving the puzzle why episodic evolution occurs in certain lineages of the mammalian lineages, and not other lineages. In addition, previous studies have established a foundation for further experimental investigations. It will be interesting to test expression patterns, binding affinities and specificity of the leptin and the receptor, as well as the functional effects of positively selected amino acid changes identified so far. These findings emphasize on a need to study leptin and $L P R$ genes in additional mammal species that encompass varying life histories. As more mammalian species are sequenced and analyzed, additional cases of demonstrating dynamic evolution would be expected to be observed for leptin and its receptor.

This work was supported by National Natural Science Foundation of China (U0836603) and Program for New Century Excellent Talents in University (NCET). 
1 Geng J, Liang D, Jiang K, et al. Molecular evolution of the infrared sensory gene TRPA1 in snakes and implications for functional studies. PLoS One, 2011, 6: e28644

2 Areal H, Abrantes J, Esteves P J. Signatures of positive selection in Toll-like receptor (TLR) genes in mammals. BMC Evol Biol, 2011, 11: 368

3 Yu L, Wang X, Jin W, et al. Adaptive evolution of digestive RNASE1 genes in leaf-eating monkeys revisited: New insights from ten additional colobines. Mol Biol Evol, 2010, 27: 121-131

4 Yu L, Wang X, Ting N, et al. Mitogenomic analysis of Chinese snub-nosed monkeys: Evidence of positive selection in NADH dehydrogenase genes in high-altitude adaptation. Mitochondrion, 2011, 11: 497-503

5 Zhang J. Parallel adaptive origins of digestive RNases in Asian and African leaf monkeys. Nat Genet, 2006, 38: 819-823

6 Zhang J, Zhang Y P, Rosenberg H F. Adaptive evolution of a duplicated pancreatic ribonuclease gene in a leaf-eating monkey. Nat Genet, 2002, 30: 411-415

7 Yu L, Jin W, Wang J X, et al. Characterization of TRPC2, an essential genetic component of VNS chemoreception, provides insights into the evolution of pheromonal olfaction in secondary-adapted marine mammals. Mol Biol Evol, 2010, 27: 1467-1477

8 Yu L, Zhang Y P. The unusual adaptive expansion of pancreatic ribonuclease gene in carnivora. Mol Biol Evol, 2006, 23: 2326-2335

9 Yu L, Jin W, Zhang X, et al. Evidence for positive selection on the leptin gene in cetacea and pinnipedia. PLoS One, 2011, 6: e26579

10 Tartaglia L A. The leptin receptor. J Biol Chem, 1997, 272: 60936096

11 Considine R V, Caro J F. Leptin and the regulation of body weight. Int J Biochem Cell B, 1997, 29: 1255-1272

12 Zhang Y, Proenca R, Maffei M, et al. Positional cloning of the mouse obese gene and its human homologue. Nature, 1994, 372: 425-432

13 Campfield L A, Smith F J, Guisez Y, et al. Recombinant mouse OB protein: Evidence for a peripheral signal linking adiposity and central neural networks. Science, 1995, 269: 546-549

14 Friedman J M, Halaas J L. Leptin and the regulation of body weight in mammals. Nature, 1998, 395: 763-770

15 Houseknecht K L, Baile C A, Matteri R L, et al. The biology of leptin: A review. J Anim Sci, 1998, 76: 1405-1420

16 Andrews M T, Squire T L, Bowen C M, et al. Low-temperature carbon utilization is regulated by novel gene activity in the heart of a hibernating mammal. Proc Natl Acad Sci USA, 1998, 95: 8392

17 Halaas J L, Gajiwala K S, Maffei M, et al. Weight-reducing effects of the plasma protein encoded by the obese gene. Science, 1995, 269: 543-546

18 Stephens T W, Basinski M, Bristow P K, et al. The role of neuropeptide $\mathrm{Y}$ in the antiobesity action of the obese gene product. Nature, 1995, 377: 530-532

19 Kennedy G C. The role of depot fat in the hypothalamic control of food intake in the rat. P Roy Soc Lond B Bio, 1953, 140: 578-596

20 Friedman J M, Leibel R L, Bahary N, et al. Genetic analysis of complex disorders. Molecular mapping of obesity genes in mice and humans. Ann N Y Acad Sci, 1991, 630: 100-115

21 Pelleymounter M A, Cullen M J, Baker M B, et al. Effects of the obese gene product on body weight regulation in $o b / o b$ mice. Science, 1995, 269: 540-543

22 Montague C T, Farooqi I S, Whitehead J P, et al. Congenital leptin deficiency is associated with severe early-onset obesity in humans. Nature, 1997, 387: 903-908

23 Strobel A, Issad T, Camoin L, et al. A leptin missense mutation associated with hypogonadism and morbid obesity. Nat Genet, 1998, 18: 213-215

24 Benner S A, Trabesinger N, Schreiber D. Post-genomic science: Converting primary structure into physiological function. Adv Enzyme Regul, 1998, 38: 155-180

25 Lee D W, Leinung M C, Rozhavskaya-Arena M, et al. Leptin and the treatment of obesity: Its current status. Eur J Pharmacol, 2002, 440: $129-139$
26 Zhang F, Basinski M B, Beals J M, et al. Crystal structure of the obese protein leptin-E100. Nature, 1997, 387: 206-209

27 Madej T, Boguski M S, Bryant S H. Threading analysis suggests that the obese gene product may be a helical cytokine. FEBS Lett, 1995, 373: 13-18

28 Kline A D, Becker G W, Churgay L M, et al. Leptin is a four-helix bundle: Secondary structure by NMR. FEBS Lett, 1997, 407: 239242

29 Iwase M, Kimura K, Sasaki N, et al. Canine leptin: cDNA cloning, expression and activity of recombinant protein. Res Vet Sci, 2000, 68: 109-114

30 Hotta K, Gustafson T A, Ortmeyer H K, et al. Regulation of obese $(o b)$ mRNA and plasma leptin levels in rhesus monkeys. Effects of insulin, body weight, and non-insulin-dependent diabetes mellitus. J Biol Chem, 1996, 271: 25327-25331

31 Ji S, Willis G M, Scott R R, et al. Partial cloning and expression of the bovine leptin gene. Anim Biotechnol, 1998, 9: 1-14

32 Sasaki N, Shibata H, Honjoh T, et al. CDNA cloning of feline leptin and its mRNA expression in adipose tissue. J Vet Med Sci, 2001, 63: 1115-1120

33 Hammond J A, Bennett K A, Walton M J, et al. Molecular cloning and expression of leptin in gray and harbor seal blubber, bone marrow, and lung and its potential role in marine mammal respiratory physiology. Am J Physiol-Reg I 2005, 289: R545-R553

34 Yang J, Bromage T G, Zhao Q, et al. Functional evolution of leptin of Ochotona curzoniae in adaptive thermogenesis driven by cold environmental stress. PLoS One, 2011, 6: e19833

35 Yang J, Wang Z L, Zhao X Q, et al. Natural selection and adaptive evolution of leptin in the ochotona family driven by the cold environmental stress. PLoS One, 2008, 3: e1472

36 Benner S A, Caraco M D, Thomson J M, et al. Planetary biology-paleontological, geological, and molecular histories of life. Science, 2002, 296: 864-868

37 Benner S A, Chamberlin S G, Liberles D A, et al. Functional inferences from reconstructed evolutionary biology involving rectified databases-An evolutionarily grounded approach to functional genomics. Res Microbiol, 2000, 151: 97-106

38 Benner S A, Gaucher E A. Evolution, language and analogy in functional genomics. Trends Genet, 2001, 17: 414-418

39 Berglund A C, Wallner B, Elofsson A, et al. Tertiary windowing to detect positive diversifying selection. J Mol Evol, 2005, 60: 499504

40 Gaucher E A, Miyamoto M M, Benner S A. Evolutionary, structural and biochemical evidence for a new interaction site of the leptin obesity protein. Genetics, 2003, 163: 1549-1553

41 Liberles D A. Evaluation of methods for determination of a reconstructed history of gene sequence evolution. Mol Biol Evol, 2001, 18 2040-2047

42 Liberles D A, Schreiber D R, Govindarajan S, et al. The adaptive evolution database (TAED). Genome Biol, 2001, 2: RESEARCH 00281-6

43 Siltberg J, Liberles D. A simple covarion-based approach to analyse nucleotide substitution rates. J Evolution Biol, 2002, 15: 588-594

44 Yuan L, Zhao X, Lin B, et al. Adaptive evolution of leptin in heterothermic bats. PLoS One, 2011, 6: e27189

45 Russo F, De Girolamo P, Neglia S, et al. Immunohistochemical and immunochemical characterization of the distribution of leptin-like proteins in the gastroenteric tract of two teleosts (Dicentrarchus labrax and Carassius auratus L.) with different feeding habits. Microsc Res Tech, 2011, 74: 714-719

46 Storey K B, Storey J M, Tanino K. Strategies of molecular adaptation to climate change: The challenges for amphibians and reptiles. In: Temperature Adaptation in a Changing Climate. Wallingford, UK: CABI Publishers, 2011, 3: 98

47 Huntley B, Webb III T. Migration: species' response to climatic variations caused by changes in the earth's orbit. J Biogeogr, 1989: $5-19$

48 Wright B E. Stress-directed adaptive mutations and evolution. Mol Microbiol, 2004, 52: 643-650 
49 Xu S, Luosang J, Hua S, et al. High altitude adaptation and phylogenetic analysis of Tibetan horse based on the mitochondrial genome. J Genet Genomics, 2007, 34: 720-729

50 Luo Y, Gao W, Gao Y, et al. Mitochondrial genome analysis of Ochotona curzoniae and implication of cytochrome $c$ oxidase in hypoxic adaptation. Mitochondrion, 2008, 8: 352-357

51 Da Fonseca R R, Johnson W E, O'Brien S J, et al. The adaptive evolution of the mammalian mitochondrial genome. BMC Genomics, 2008, 9: 119

52 Gering E, Opazo J, Storz J F. Molecular evolution of cytochrome b in high-and low-altitude deer mice (genus Peromyscus). Heredity, 2008, 102: 226-235

53 Hassanin A, Ropiquet A, Couloux A, et al. Evolution of the mitochondrial genome in mammals living at high altitude: New insights from a study of the tribe Caprini (Bovidae, Antilopinae). J Mol Evol, 2009, 68: 293-310

54 Ning T, Xiao H, Li J, et al. Adaptive evolution of the mitochondrial ND6 gene in the domestic horse. Genet Mol Res, 2010, 9: 144-150

55 Wang B, Zhang Y B, Zhang F, et al. On the origin of Tibetans and their genetic basis in adapting high-altitude environments. PLoS One, 2011, 6: e17002

56 Xu S Q, Yang Y Z, Zhou J, et al. A mitochondrial genome sequence of the Tibetan antelope (Pantholops hodgsonii). Geno Prot Bioinfo, 2005, 3: 5-17

57 Storz J F. Hemoglobin function and physiological adaptation to hypoxia in high-altitude mammals. J Mammal, 2007, 88: 24-31

58 Storz J F, Runck A M, Sabatino S J, et al. Evolutionary and functional insights into the mechanism underlying high-altitude adaptation of deer mouse hemoglobin. Proc Natl Acad Sci USA, 2009, 106 14450-14455

59 Storz J F, Runck A M, Moriyama H, et al. Genetic differences in hemoglobin function between highland and lowland deer mice. J Exp Biol, 2010, 213: 2565-2574

60 McCracken K G, Barger C P, Sorenson M D. Phylogenetic and structural analysis of the $\mathrm{HbA}(\mathrm{aA} / \mathrm{bA})$ and $\mathrm{HbD}(\mathrm{aD} / \mathrm{bA})$ hemoglobin genes in two high-altitude waterfowl from the Himalayas and the Andes: Bar-headed goose (Anser indicus) and Andean goose (Chloephaga melanoptera). Mol Phylogenet Evol, 2010, 56: 649_ 658

61 Bigham A, Bauchet M, Pinto D, et al. Identifying signatures of natural selection in Tibetan and Andean populations using dense genome scan data. PLoS Genet, 2010, 6: e1001116

62 Bigham A W, Mao X, Mei R, et al. Identifying positive selection candidate loci for high-altitude adaptation in Andean populations. Hum Genomics, 2009, 4: 79-90

63 Beall C M, Cavalleri G L, Deng L, et al. Natural selection on EPAS1 (HIF $2 \alpha$ ) associated with low hemoglobin concentration in Tibetan highlanders. Proc Natl Acad Sci USA, 2010, 107: 11459

64 Simonson T S, Yang Y, Huff C D, et al. Genetic evidence for high-altitude adaptation in Tibet. Science's STKE, 2010, 329: 72

65 Yi X, Liang Y, Huerta-Sanchez E, et al. Sequencing of 50 human exomes reveals adaptation to high altitude. Science's STKE, 2010, 329: 75

66 Peng Y, Yang Z, Zhang H, et al. Genetic variations in Tibetan populations and high-altitude adaptation at the Himalayas. Mol Biol Evol, 2011, 28: 1075-1081

67 Tissot van Patot M C, Gassmann M. Hypoxia: Adapting to high Altitude by mutating EPAS-1, the gene encoding HIF- $2 \alpha$. High Al Med Biol, 2011, 12: 157-167

68 Grasso $\mathrm{P}$, Leinung M C, Ingher S P, et al. In vivo effects of leptin-related synthetic peptides on body weight and food intake in female ob/ob mice: Localization of leptin activity to domains between amino acid residues 106-140. Endocrinology, 1997, 138: 14131418

69 Grasso P, Leinung M C, Lee D W. Epitope mapping of secreted mouse leptin utilizing peripherally administered synthetic peptides. Regul Pept, 1999, 85: 93-100

70 Li B, Chen C, Ji W, et al. Seasonal home range changes of the sichuan snub-nosed monkey (Rhinopithecus roxellana) in the Qinling mountains of China. Folia Primatol, 2000, 71: 375-386

71 Kirkpatrick R C. Ecology and behavior in snub-nosed and douc langurs. In: Jablonski N G, ed. The Natural History of the Docus and Snub-nosed Monkeys. Singapore: World Scientific, 1998. 155-190

72 Xiang Z F, Yu Y, Yang M, et al. Does flagship species tourism benefit conservation? A case study of the golden snub-nosed monkey in Shennongjia National Nature Reserve. Chin Sci Bull, 2011, 56: 2553-2558

73 Pan H J, Shi F L, Chang Z F, et al. Mitochondrial DNA variation analysis suggests extreme low genetic diversity in Guizhou snubnosed monkeys (Rhinopithecus brelichi). Chin Sci Bull, 2011, 56: 2541-2544

74 Wang X P, Jin W, Yu L, et al. Molecular evolution of stressresponse gene Leptin in high-altitude Chinese snub-nosed monkeys (Rhinopithecus genus). Chin Sci Bull, 2010, 55: 4132-4135

75 Weber R E. High-altitude adaptations in vertebrate hemoglobins. Resp Physiol Neurob, 2007, 158: 132-142

76 Moore L G, Zamudio S, Zhuang J, et al. Analysis of the myoglobin gene in Tibetans living at high altitude. High Alt Med Biol, 2002, 3: 39-47

77 Botney M D, Bahadori L, Gold L I. Vascular remodeling in primary pulmonary hypertension. Potential role for transforming growth factor-beta. Am J Pathol, 1994, 144: 286-295

78 Isaac D D, Andrew D J. Tubulogenesis in Drosophila: A requirement for the trachealess gene product. Genes Dev, 1996, 10: 103117

79 Lopez-Barneo J, Pardal R, Ortega-Saenz P. Cellular mechanism of oxygen sensing. Annu Rev Physiol, 2001, 63: 259-287

80 Saraste M. Oxidative phosphorylation at the fin de siecle. Science, 1999, 283: 1488-1493

81 McClellan D A, Palfreyman E J, Smith M J, et al. Physicochemical evolution and molecular adaptation of the cetacean and artiodactyl cytochrome b proteins. Mol Biol Evol, 2005, 22: 437-455

82 Wang Z, Yuan L, Rossiter S J, et al. Adaptive evolution of 5'HoxD genes in the origin and diversification of the cetacean flipper. Mol Biol Evol, 2009, 26: 613-622

83 Worthy G A J, Lavigne D. Energetics of fasting and subsequent growth in weaned harp seal pups, Phoca groenlandica. Can J Zool, 1983, 61: 447-456

84 Young R A. Fat, energy and mammalian survival. Am Zool, 1976, 16: 699-710

85 Whittow G. Thermoregulatory adaptations in marine mammals: Interatting effects of exercise and body mass. Mar Mammal Sci, 1987, 3: $220-241$

86 Ortiz R M, Wade C E, Ortiz C L. Effects of prolonged fasting on plasma cortisol and $\mathrm{TH}$ in postweaned northern elephant seal pups. Am J Physiol-Reg I, 2001, 280: R790-795

87 Reilly J, Fedak M, Thomas D, et al. Water balance and the energetics of lactation in grey seals (Halichoerus grypus) as studied by isotopically labelled water methods. J Zool, 1996, 238: 157-165

88 Mokrasch L, Grady H, Grisolia S. Thermogenic and adaptive mechanisms in hibernation and arousal from hibernation. Am J Phy-Leg Content, 1960, 199: 945-949

89 Moss C F, Sinha S R. Neurobiology of echolocation in bats. Curr Opin Neurobio, 2003, 13: 751-758

90 Lyman C. Thermoregulation and metabolism in bats. In: Wimsatt W A, ed. Biology of Bats. London: Acadenic Press, 1970. 266-299

91 Ormseth O A, Nicolson M, Pelleymounter M, et al. Leptin inhibits prehibernation hyperphagia and reduces body weight in arctic ground squirrels. Am J Physiol-Reg I, 1996, 271: R1775-R1779

92 Townsend K L, Kunz T H, Widmaier E P. Changes in body mass, serum leptin, and mRNA levels of leptin receptor isoforms during the premigratory period in Myotis lucifugus. J Comp Physiol B, 2008, 178: 217-223

93 Kronfeld-Schor N, Richardson C, Silvia B A, et al. Dissociation of leptin secretion and adiposity during prehibernatory fattening in little brown bats. Am J Physiol Reg, 2000, 279: R1277-1281

94 Concannon P, Levac K, Rawson R, et al. Seasonal changes in serum leptin, food intake, and body weight in photoentrained woodchucks. 
Am J Physiol-Reg I, 2001, 281: R951-959

95 Florant G L, Porst H, Peiffer A, et al. Fat-cell mass, serum leptin and adiponectin changes during weight gain and loss in yellow-bellied marmots (Marmota flaviventris). J Comp Physiol B, 2004, 174: 633-639

96 Roy V K, Krishna A. Regulation of leptin synthesis during adipogenesis in males of a vespertilionid bat, Scotophilus heathi. J Exp Biol, 2011, 214: 1599-1606

97 Srivastava R K, Krishna A. Increased circulating leptin level inhibits folliculogenesis in vespertilionid bat, Scotophilus heathii. Mol Cell Endocrinol, 2011, 337: 24-35

98 Banerjee A, Udin S, Krishna A. Regulation of leptin synthesis in white adipose tissue of the female fruit bat, Cynopterus sphinx: Role of melatonin with or without insulin. Exp Physiol, 2010, 96: 216-225

99 Nieminen P, Hyvarinen H, Kakela R, et al. Plasma leptin and thyroxine of mink (Mustela vison) vary with gender, diet and subchronic exposure to PCBs. Cmop Biochem Phys A, 2000, 127: 515-522

$100 \mathrm{He}$ L, Pan Y, He G, et al. Structural and functional studies of leptins from hibernating and non-hibernating bats. Gen omp Endocr, 2010, 168: 29-35

101 Masuzaki H, Ogawa Y, Sagawa N, et al. Nonadipose tissue production of leptin: Leptin as a novel placenta-derived hormone in humans. Nat Med, 1997, 3: 1029-1033

102 Casabiell X, Pineiro V, Tome M A, et al. Presence of leptin in colostrum and/or breast milk from lactating mothers: A potential role in the regulation of neonatal food intake. J Clin Endocr Metab, 1997, 82: 4270-4273

103 Senaris R, Garcia-Caballero T, Casabiell X, et al. Synthesis of leptin in human placenta. Endocrinology, 1997, 138: 4501-4504

104 Bado A, Levasseur S, Attoub S, et al. The stomach is a source of leptin. Nature, 1998, 394: 790-793

105 Laharrague P, Larrouy D, Fontanilles A M, et al. High expression of leptin by human bone marrow adipocytes in primary culture. FASEB J, 1998, 12: 747-752

106 Arnould J P, Morris M J, Rawlins D R, et al. Variation in plasma leptin levels in response to fasting in Antarctic fur seals (Arctocephalus gazella). J Comp Physiol B, 2002, 172: 27-34

107 Torday J S, Sun H, Wang L, et al. Leptin mediates the parathyroid hormone-related protein paracrine stimulation of fetal lung maturation. Am J Physiol-Lung C, 2002, 282: L405-410

108 Chen H, Charlat O, Tartaglia L A, et al. Evidence that the diabetes gene encodes the leptin receptor: Identification of a mutation in the leptin receptor gene in db/db mice. Cell, 1996, 84: 491-495

109 Lee G H, Proenca R, Montez J M, et al. Abnormal splicing of the leptin receptor in diabetic mice. Nature, 1996, 379: 632-635

110 Peelman F, Iserentant H, De Smet A S, et al. Mapping of binding site III in the leptin receptor and modeling of a hexameric leptin.leptin receptor complex. J Biol Chem, 2006, 281: 15496-15504

111 Tartaglia L A, Dembski M, Weng X, et al. Identification and expression cloning of a leptin receptor, OB-R. Cell, 1995, 83: 1263-1271

112 Clement K, Vaisse C, Lahlou N, et al. A mutation in the human leptin receptor gene causes obesity and pituitary dysfunction. Nature, 1998, 392: 398-401

113 Ghilardi N, Ziegler S, Wiestner A, et al. Defective STAT signaling by the leptin receptor in diabetic mice. Proc Natl Acad Sci USA, 1996, 93: 6231-6235

114 Kapitonov V V, Jurka J. The long terminal repeat of an endogenous retrovirus induces alternative splicing and encodes an additional carboxy-terminal sequence in the human leptin receptor. J Mol Evol, 1999, 48: 248-251

115 Fong T M, Huang R R, Tota M R, et al. Localization of leptin binding domain in the leptin receptor. Mol Pharmacol, 1998, 53: 234-240

116 Peelman F, Van Beneden K, Zabeau L, et al. Mapping of the leptin binding sites and design of a leptin antagonist. J Biol Chem, 2004, 279: 41038-41046

117 Sandowski Y, Raver N, Gussakovsky E E, et al. Subcloning, expression, purification, and characterization of recombinant human leptinbinding domain. J Biol Chem, 2002, 277: 46304-46309

118 Zabeau L, Defeau D, Van der Heyden J, et al. Functional analysis of leptin receptor activation using a Janus kinase/signal transducer and activator of transcription complementation assay. Mol Endocrinol, 2004, 18: 150-161

119 de Vos A M, Ultsch M, Kossiakoff A A. Human growth hormone and extracellular domain of its receptor: Crystal structure of the complex. Science, 1992, 255: 306

120 Liu J C, Makova K D, Adkins R M, et al. Episodic evolution of growth hormone in primates and emergence of the species specificity of human growth hormone receptor. Mol Biol Evol, 2001, 18: 945-953

$121 \mathrm{Li} \mathrm{Y,} \mathrm{Wallis} \mathrm{M,} \mathrm{Zhang} \mathrm{Y} \mathrm{P.} \mathrm{Episodic} \mathrm{evolution} \mathrm{of} \mathrm{prolactin} \mathrm{receptor}$ gene in mammals: Coevolution with its ligand. J Mol Endocrinol, 2005, 35: 411-419

Open Access This article is distributed under the terms of the Creative Commons Attribution License which permits any use, distribution, and reproduction in any medium, provided the original author(s) and source are credited. 